\title{
3D REPRESENTATION OF THE 19TH CENTURY BALKAN ARCHITECTURE USING SCALED MUSEUM-MAQUETTE AND PHOTOGRAMMETRY METHODS
}

\author{
E. Georgiou ${ }^{\text {a }}$ E. Karachaliou ${ }^{\text {a }}$ E. Stylianidis ${ }^{\mathrm{a}}$

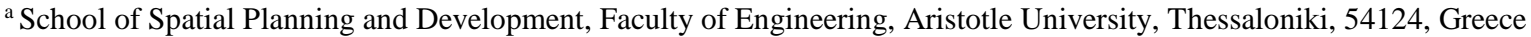 \\ efthimios_georgiou@yahoo.gr; ekaracha@plandevel.auth.gr; sstyl@auth.gr
}

\section{Commission II}

KEY WORDS: Balkan architecture, scaled - museum maquette, photogrammetry

\begin{abstract}
:
Characteristic example of the Balkan architecture of the $19^{\text {th }}$ century, consists the "Tower house" which is found in the region of Epirus and Western Macedonia, Greece. Nowadays, the only information about these heritage buildings could be abstracted by the architectural designs on hand and the model - Tower that is being displayed in the Folklore Museum of the Municipality of Kozani, Greece, as a maquette. The current work generates a scaled 3D digital model of the "Tower house", by using photogrammetry techniques applied on the model-maquette that is being displayed in the Museum exhibits.
\end{abstract}

\section{INTRODUCTION}

\subsection{Cultural heritage preservation}

According to Unesco's definition, the term "Cultural Heritage" refers to several main categories of tangible or untangible heritage i.e. paintings, sculptures, monuments, archaeological sites, oral traditions, performing arts, rituals etc. (Unesco, 2017). The majority of the above types of cultural heritage can be found within a city/town. The cultural heritage tangible or intangible includes great historical and cultural value and integrates the identity of the respective civilizations, thus it is worth preservation in order to retain its cultural significance while ensuring its accessibility to present and future generations (Kalamarova et al., 2015).

Over the last decades, innovative 3D digitization and geomatics technologies has entered the field of cultural heritage, mainly in order to meet the needs of preservation, management and protection. The main objectives are to (Gomes et al., 2014):

ensure that the information regarding the significant historical characteristics (shape, appearance) of a cultural heritage entity will be reserved in case of natural or other damages

allow the dissemination of digital representations i.e. for virtual museums purposes

uncover art forgery

collect and study information that is difficult to perform it in the real object

Moreover, as Paquet and Viktor (2005) notes, 3D technologies could respond to the problems of monitoring, preserving and public accessibility of cultural heritage. In particular Paquet (2005) points out that cultural heritage sites are threaten by natural degradation over the time which is further affected by their exposure to natural elements and to the public. A virtual representation of the original heritage object could replace the later and therefore protect it and support its long term preservation.

\subsection{D representation of a demolished or lost heritage}

Preventive actions of cultural heritage could be carried out either in situ or virtually, using photogrammetry and computer vision techniques. However, the field visit and the data acquisition is not always attainable in case the monument is demolished or lost (Stathopoulou et al., 2015). Surveying, photogrammetry and laser scanning techniques are usually combined as for producing an integrated and accurate $3 \mathrm{D}$ representation of the historic element but this is not easily achievable in case that the original heritage structure does not exist. Going through the literature, many different approaches have been developed so far in order to obtain digital info of an object that is demolished or does not exist anymore, such as crowdsourcing (Stathopoulou et al., 2015) or scaled maquettes (Guerra \& Vernier, 2011), (Batelli et al., 2011).

In the field of architecture, the use of scaled simulations of an object was always necessary and aided to the representation of entities that are about to be built or that do not exist anymore. These simulations vary from scale models, maquettes, point clouds, and 3D digital models (Baletti et al., 2011), and follow the technological advances in the era of digital representation. Nowadays, maquette models in combination with modern geomatics tools, can be used as database for the reconstruction of a monument or the 3D representation of a structure that has been destroyed or demolished (Guerra and Vernier, 2011).

The current work generates a scaled 3D digital model of the "Tower house" - heritage Balkan architecture building from the $19^{\text {th }}$ century- by using photogrammetry techniques applied on its model-maquette that is being displayed in the Folklore Museum of the Municipality of Kozani, Greece (Figure 1). Thereby, it is achieved the digital representation of considerable heritage that does not exist anymore in real and consequently cannot be acquired and studied. 


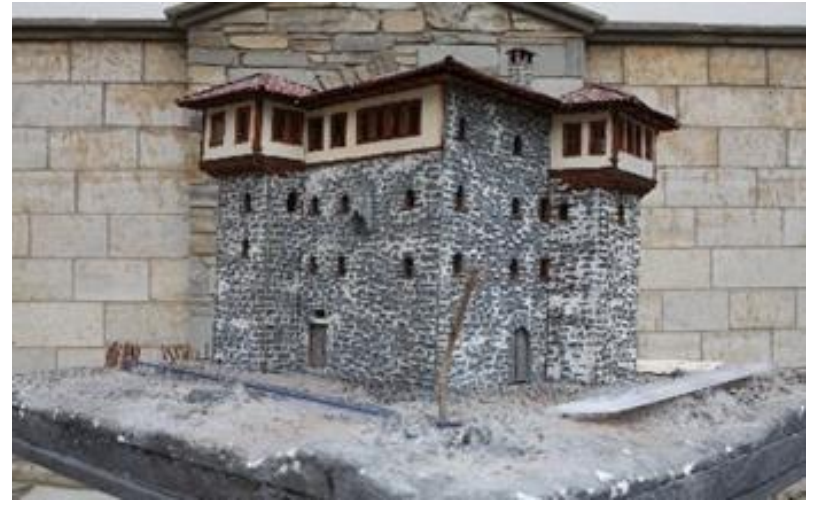

Figure 1: Model maquette of Tower House in the Folklore Museum of the Municipality of Kozani, Greece

\section{HISTORICAL BACKGROUND}

\subsection{9th century Balkan cities}

The $19^{\text {th }}$ century was the period during which the Balkan map was formed with the new Balkan states and the modernisation of the Ottoman Empire began. The development of the Balkan area and cities that period is noticeable, especially in terms of architecture and urban planning, where radical changes took place within what it's used to be called as "Europeanisation" (Minea, 2014). However, by the end of the century, the architectural styles tend to form their own national kind, which was characterised by the imported Western styles integrated with the history, the tradition and the national ideology of the countries responding to the prevailing socio-political and economic conditions of the region (Minea, 2014).

The transition period in the Balkans lasted about five decades, from 1869 when the modernization commenced, until 1922 when refugees begun to settle and the first arbitrary slumsrefugee neighborhoods appeared. The 19th century is described as the century of revolutions while the big empires were collapsing and small ethnic groups were trying to form a separate ethnic identity and to establish new nation-states (Hobsbawm 1994).

The changes towards cities' regeneration, imply the intention of the State for modernization. Cities become to appear as the places where the State applied all the new policies regarding the urban space structure, the activities and the institutions (Yerolympos, 1996)

The new urban planning, inspired by relevant European practices of that period, was intended to address problems such as the (Mclntyre, 1988):
rapid population growth
bad hygiene conditions
need to improve/raise citizens' quality of life
need to develop transport networks
lack of infrastructure able to support the trade and the transactions

Within this concept, Balkan architecture was formed in order to respond to the new socio-economic conditions. In particular, in South-Western Balkans, characteristic example of the traditional architecture of that period, consists the "Tower house" (Figure 2).

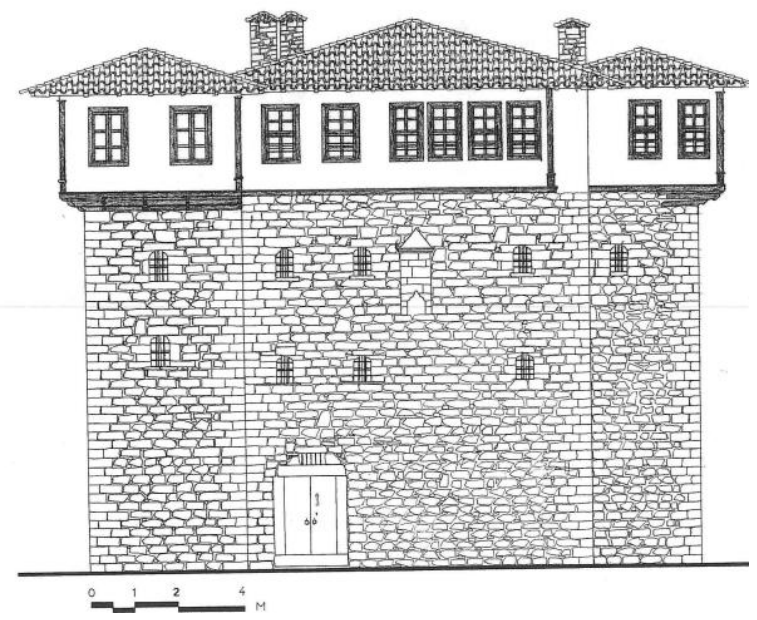

Figure 2: Tower House

\subsection{Tower-traditional architecture}

In the concept of an interview conducted with the president of the Folklore Museum of the Municipality of Kozani, Greece, Mr. Agelis Polinikis, valuable information collected regarding the origin and the characteristics of the Tower-traditional architecture.

The birth of the tower house is placed in the region of Epirus and Western Macedonia, where it secured the defensive protection of the inhabitants of the mountainous part of the Pindos mountain range, from raiders and looting, which were a common phenomenon in the late 19th century. There were times that the residence served as accommodation for migrants and moving populations (traders, nomads). The construction of the "Tower house" was based on stone and wood materials. Extra feature served the orientation rooms of the "Tower house", which provided for energy savings purposes. The inner side of the building consist of the stairway, the accommodation space, rooms, hospitality area etc.

The Tower was a square multilevel single building, where originally the construction did not have any projections in points that intersect the sides. The entrance to the Interior of the building was constructed on a high point of land. The architecture is defined by a strict geometrical form, with 97 neat, clear volumes. In addition to the outdoor courtyard area, which contributed to the daily living, is prominent for its vitality, as part of the daily activities took place in it.

The functional significance of the space structure was crucial, because it was the intermediate space in a smooth transition from the outside (public), to the inside (private). Subsequently, access to the inside was achieved via a floating wooden staircase and, later on, via a built-in external staircase. The following illustration (Figure 3) shows the view from the inner part of the Tower house.

Its use originally contributed to the protection against predatory raids and looting, which forced residents to constant vigilance. Along the way, its use was transformed and the traits of the old character of the building were lost so that it assumed the form of a mansion. 

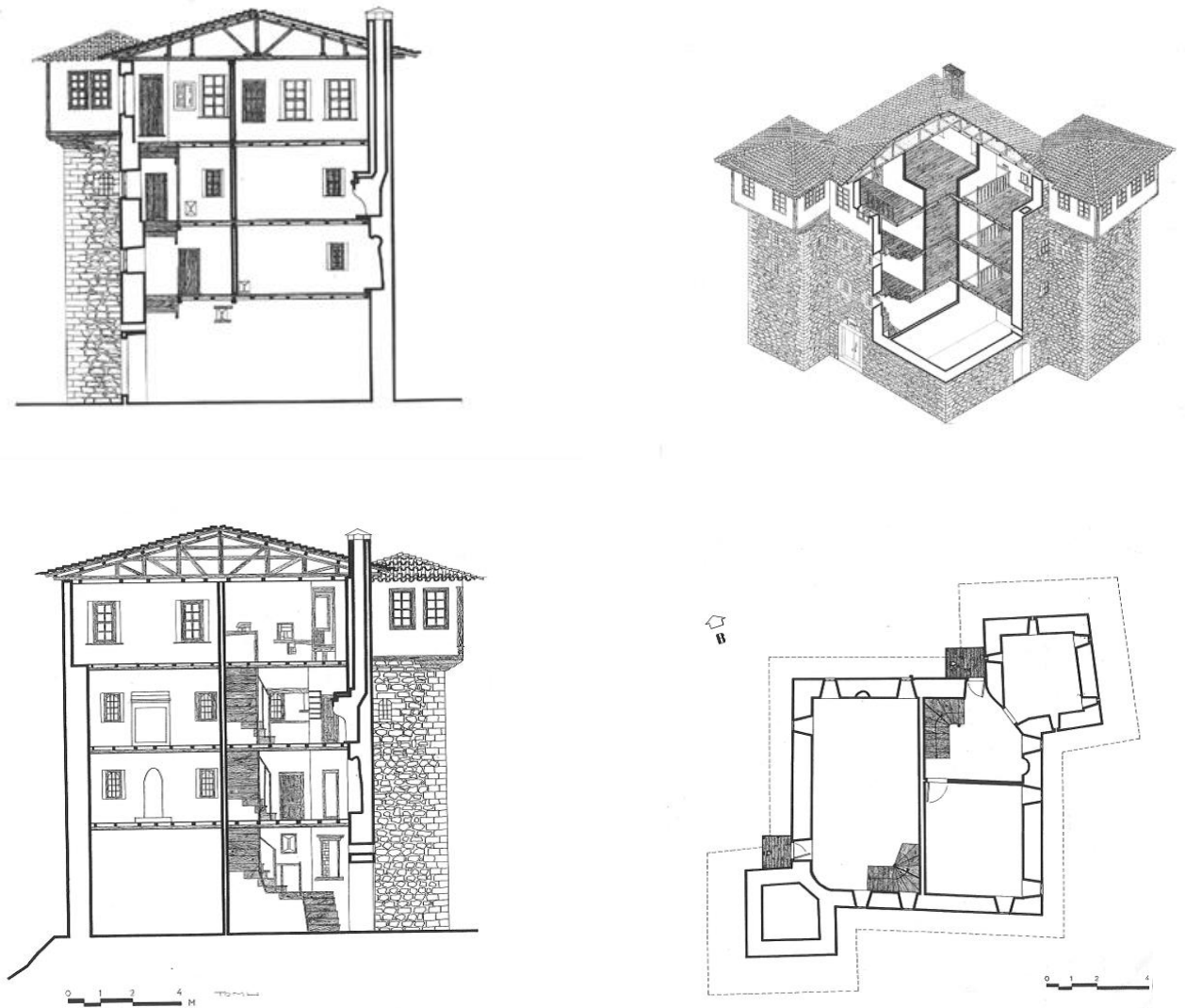

Figure 3: Intersections of the Tower House

\section{3D DIGITAL REPRESENTATION}

\subsection{Object description}

The current work aims to present that 3D technologies could be used in order to visualize and represent heritage objects that its' original structure does not exist anymore and thus cannot be captured. The model-maquette of the Tower constitutes an exhibit of the Folklore Museum of the Municipality of Kozani, Greece.
This model-maquette (Figure 5) along with the architecture designs on hand are the only available visualized data that exist for this cultural heritage architecture.

Through photogrammetry data acquisition of the model maquette and by using the architectural designs in order to extract information regarding the real object's dimensions, it is possible to produce a reliable and accurate 3D model of Tower house ( Figure 4).

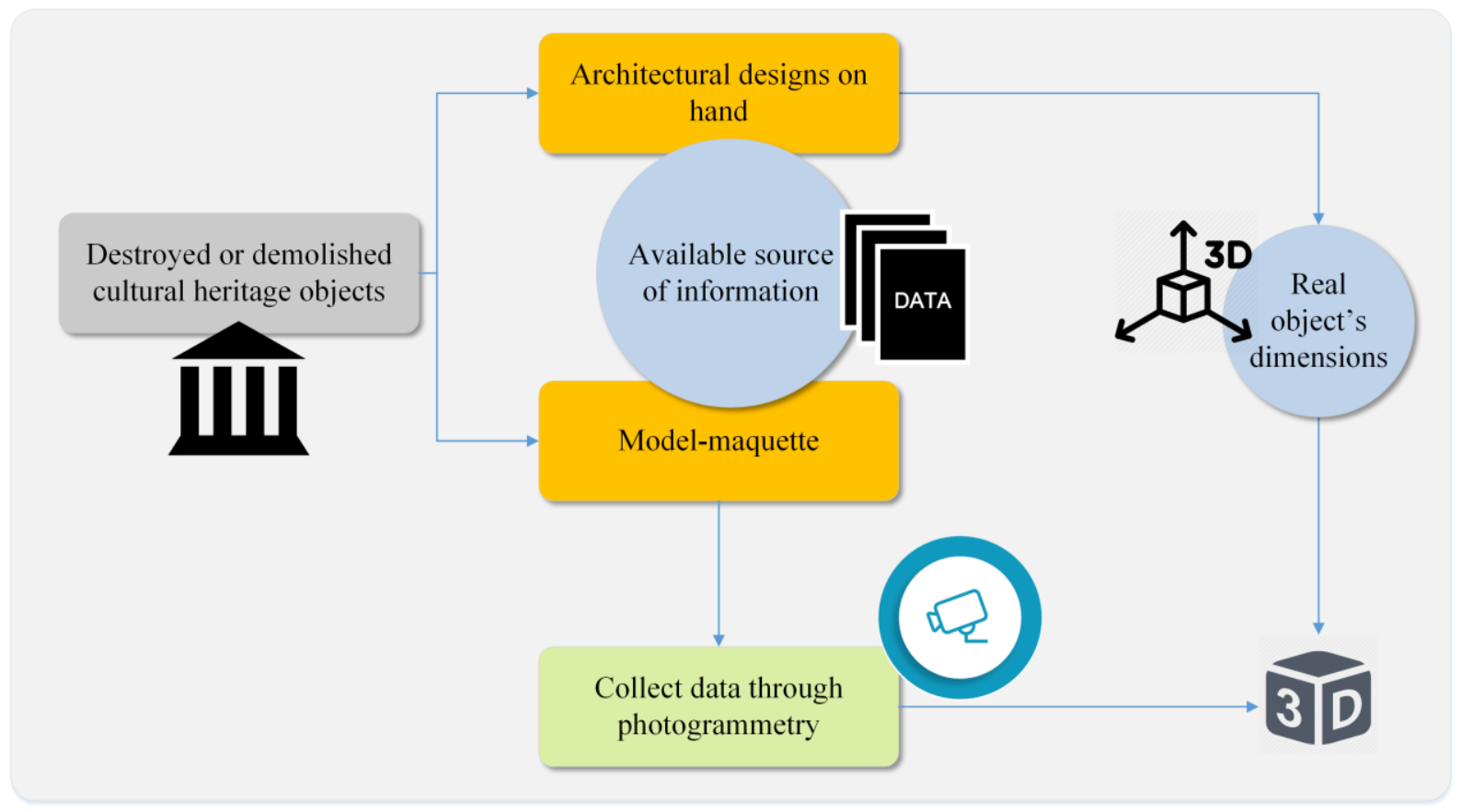

Figure 4: Workflow of the 3D representation of cultural heritage structures that does not exist anymore 

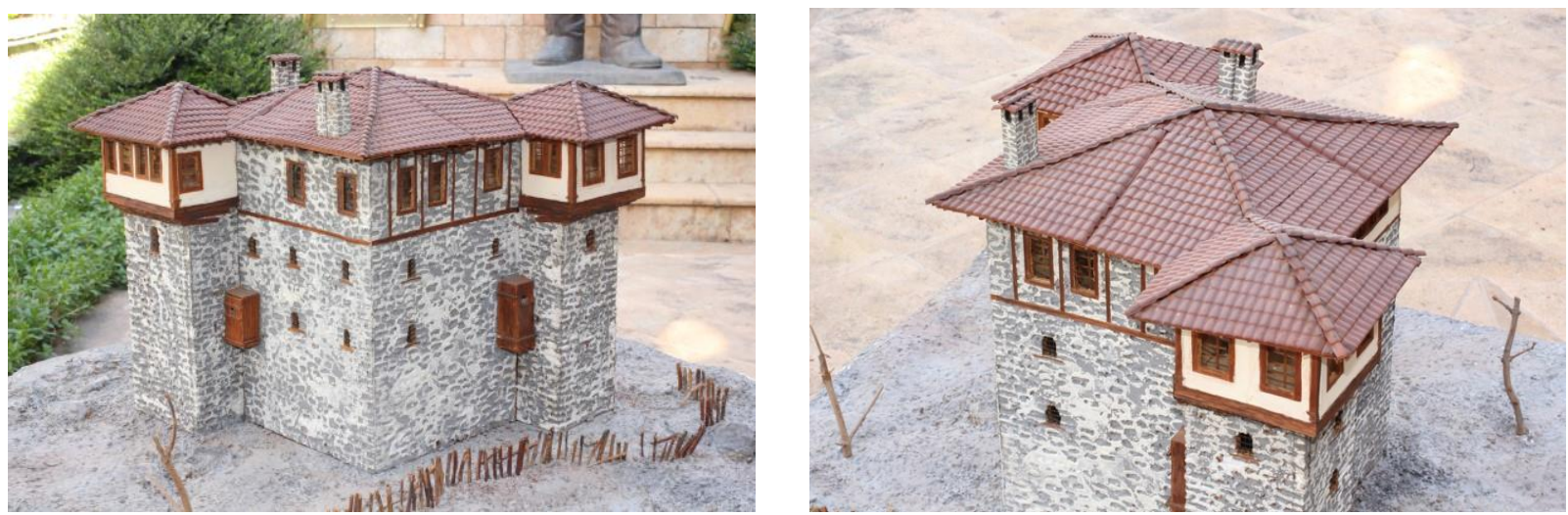

Figure 5: The model-maquette displayed in Folklore Museum of the Municipality of Kozani, Greece

Specific dimensions of the model-maquette depicted in Figure 5 , are represented in the following table (Table 1).

Table 1: Model-maquette's dimensions

\begin{tabular}{|c|c|c|}
\hline $\begin{array}{c}\text { Measurable } \\
\text { dimension }\end{array}$ & Model Maquette $(\mathrm{cm})$ & Reality $(\mathrm{m})$ \\
\hline Window Length & 2 & 1 \\
\hline Window Height & 2,8 & 1,4 \\
\hline Side length & 15,2 & 7,70 \\
\hline $\begin{array}{c}\text { Chimney side } \\
\text { length }\end{array}$ & 1 & 0,5 \\
\hline \begin{tabular}{c} 
Chimney height \\
\hline
\end{tabular} & 3 & 1,5 \\
\hline
\end{tabular}

This model-maquette was used in order to acquire digital photogrammetric data to be processed through the Agisoft Photoscan software as described in the following paragraphs.

\subsection{Equipment \& data acquisition}

The data were acquired using the Canon EOS550D camera (Table 2). A total of 77 photos were captured in 2 strips (1 vertical \& 1 oblique - Figure 6) in a distance of $0.5 \mathrm{~m}$ from the object. The data acquisition details are presented in Table 3 .

Table 2: Canon EOS550D specifications

\begin{tabular}{|l|l|}
\hline \multicolumn{2}{|c|}{ Camera specifications } \\
\hline Model & Canon EOS550D \\
\hline Sensor Size & $22.3 \times 14.9 \mathrm{~mm}$ CMOS \\
\hline Focal Lenght & $40 \mathrm{~mm}$ \\
\hline Pixel Size & $0.109 \mathrm{~mm}$ \\
\hline Image Resolution & $5184 \times 3456$ \\
\hline
\end{tabular}

Table 3: Data acquisition details

\begin{tabular}{|l|l|}
\hline Distance & $0,5 \mathrm{~m}$ \\
\hline Focal Length & $40 \mathrm{~mm}$ \\
\hline GSD & 0.1363 \\
\hline Number of Strips & $2(1$ vertical \& 1 oblique $)$ \\
\hline Total Number of photos & 77 \\
\hline
\end{tabular}

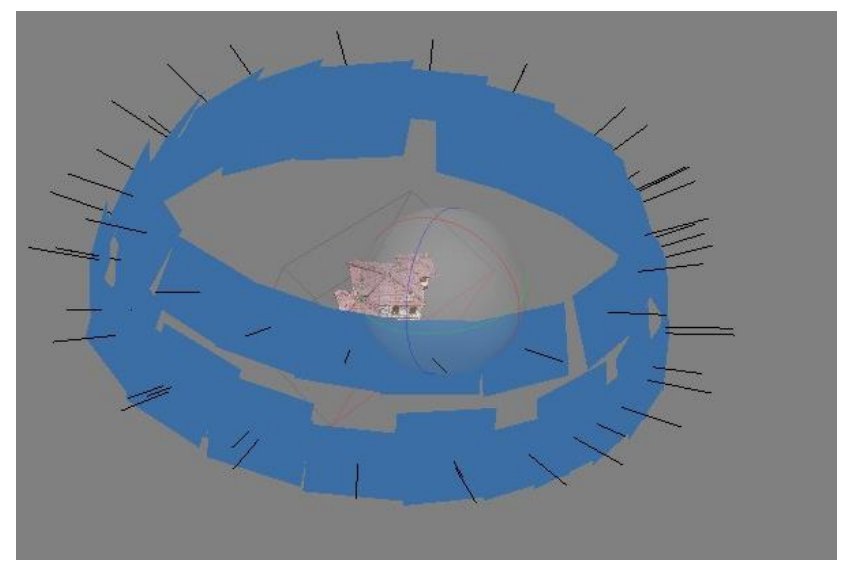

Figure 6: 2 strips of images captured

\subsection{Data processing $\&$ results}

The data were processed in Agisoft Photoscan photogrammetry software. A masking procedure was applied on the images aiming to exclude the background throughout the photo alignment process and produce a less noisy point cloud (Figure 7). Therefore, a textured mesh was produced (Figure 8).

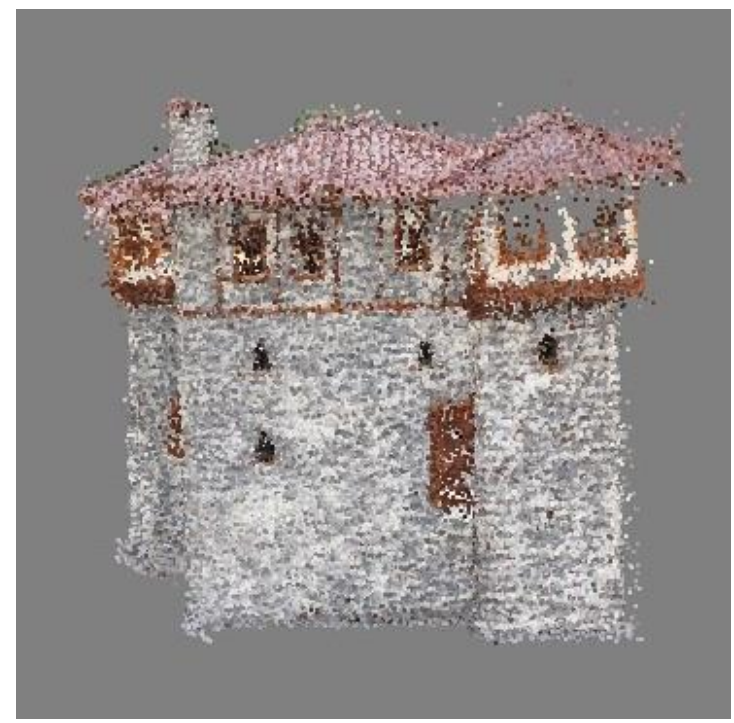

Figure 7: Dense point cloud produced in Agisoft Photoscan 


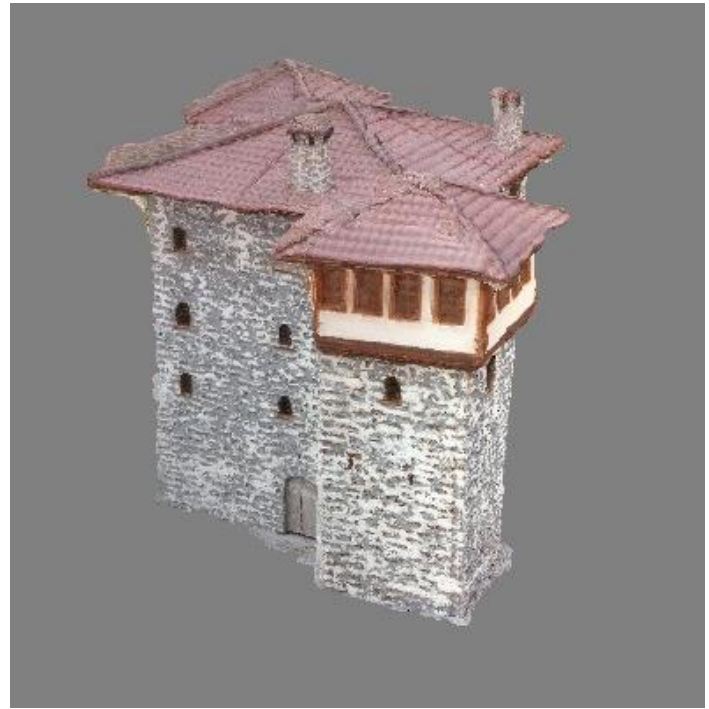

Figure 8: Textured mesh produced in Agisoft Photoscan

The produced 3D model at first was scaled using the dimensions of the model-maquette. Subsequently, the measurements from the architectural designs on hand referring to the real dimension of the tower, were also applied on the produced $3 \mathrm{D}$ model, with the purpose to produce a digital object as representative as possible to the real that does not exist anymore.

\section{CONCLUSIONS}

Cultural heritage (tangible or intangible) needs preservation as for ensuring that its significance will be readily accessible to future generations. Nowadays, photogrammetry, laser scanning techniques and geomatics technologies are used in order to collect data and information of a cultural heritage entity and to produce accurate 3D digital representations to be used for conservation purposes.

However, in many cases is not possible to acquire data of the original model due to the fact that the heritage object/structure has been demolished or lost. Therefore, scientists are trying to collect information of any other available resource such as architecture designs, maquettes, old photos, crowdsourcing etc.

A typical example of lost heritage is the Tower house, a heritage Balkan architecture building of the $19^{\text {th }}$ century. In the regions of Western Macedonia and Epirus, Greece, the Tower house characterized the traditional architecture of the period, howbeit currently there is no available any representative original structure. The only available source of information are the architectural designs on hand and the scaled model maquette, both kept in the Folklore Museum of the Municipality of Kozani, Greece.

The current work focused on creating a 3D model of the Tower house by applying photogrammetry techniques on the modelmaquette and by using the architectural designs in order to collect info regarding the original dimensions of the building.

\section{ACKNOWLEDGEMENTS}

We would like to thank sincerely the Folklore Museum of the Municipality of Kozani, Greece for the excellent collaboration as well as for providing us with all the available information regarding the "Tower House" and for giving us the possibility to acquire data of the model maquette.

Moreover, special thanks go to the president of the Museum, Mr. Agelis Polinikis, for the valuable information and the comprehensive interview that we conducted with him.

\section{REFERENCES}

Batelli, C., Guerra, F., Adami, A., (2011). From wooden maquettes to digital model: virtual reconstruction of a design path. Proceedings of the XXIIIrd International CIPA Symposium, Prague, Czech Republic.

Gomes, L., Regina Pereira Bellon, O., Silva, L. (2014). 3D reconstruction methods for digital preservation of cultural heritage: A survey. Pattern Recognition Letters, 50. Elsevier, pp. 3-14. doi: 10.1016/S2212-5671(15)00904-1

Guerra, F., Vernier P., (2011). Surveying and comparing the Arco dei Gavi and its historical wooden maquette. Proceedings of the XXIIIrd International CIPA Symposium, Prague, Czech Republic.

Hobsbawm, E., (1994). Age of extremes - The short twentieth century 1914-1991.

Kalamarova, M., Loucanova, E., Parobek, J., Supin, M., (2015). The support of the cultural heritage utilization in historical town reserves. Procedia Economics and Finance, 26. Elsevier, pp. 914-919. doi: 10.1016/S2212-5671(15)00904-1

Mclntyre, R.J., (1988). Bulgaria: Politics, Economics and Society. Pinter Pub Ltd.

Minea, C., (2014). An Image for the Nation: Architecture of the Balkan Countries at $19^{\text {th }}$ Century Universal Exhibitions in Paris

Paquet, E., Viktor, L., H., (2005). Long - term preservation of 3-D cultural heritage data related to architectural sites. ISPRS WG V/4 3D-Arch Workshop on 3D Virtual Reconstruction and Visualization of Complex Architectures.

Stathopoulou, E.K., Georgopoulos, A., Panagiotopoulos, G., Kaliampakos, D., (2015). Crowdsourcing lost cultural heritage. ISPRS Annals of the Photogrammetry, Remote Sensing and Spatial Information Sciences, Vol. II-5/W3. doi:10.5194/isprsannals-II-5-W3-295-2015

UNESCO, (2017). What is meant by "cultural heritage"? Available: http://www.unesco.org/new/en/culture/themes/illicittrafficking-of-cultural-property/unesco-database-of-nationalcultural-heritage-laws/frequently-asked-questions/definition-ofthe-cultural-heritage/

Yerolympos, A., (1996). Urban Transformations in the Balkans (1820-1920). Aspects of Balkan Town and the Remaking of Thessaloniki. University Studio Press. 